\title{
O Rio Grande do Sul e o Brasil na Historiografia do Trabalho $(1930-1945)^{*}$
}

\section{Glaucia Vieira Ramos Konrad ${ }^{* *}$ Diorge Alceno Konrad ${ }^{* * *}$}

\begin{abstract}
Resumo: Um estudo mais aprofundado da historiografia sobre as décadas de 1930 e 1940 desvela um período de intenso jogo de continuidades e rupturas, nos quais muitas especificidades regionais representaram desdobramentos particulares do contexto nacional. Sobre o Estado Novo, grande parte da historiografia defende o controle absoluto da Ditadura, por não ter ocorrido contestações, reações e questionamentos da sociedade, em geral, e dos trabalhadores, em particular, revelando a condição heteronômica diante do Estado, seja pela propaganda política e ideológica, seja pela repressão da polícia política. Este artigo revisa parte da historiografia sobre o Rio Grande do Sul e sobre o Brasil pós-1930 e debate alguns dos temas mais incidentes sobre os mundos do trabalho.
\end{abstract}

Palavras-Chaves: Mundos do Trabalho - Historiografia - Rio Grande do Sul - Brasil

\begin{abstract}
Further study of the historiography on the decades 1930 and 1940s, reveals a period intense of the continuities game and ruptures, in which, many regional specificities accounted unfoldings particular of the national context. About the New State, great part of the historiography maintains absolute control of the dictatorship, not have occurred disputes, reactions and questions of society in general and workers in particular revealing the condition heteronomic before the State, either by political propaganda and ideological, either by repression of the political police. The article reviews part the historiography on the Rio Grande do Sul and the Brazil post-1930 and debate some of the themes more incidents about on the worlds of labor.
\end{abstract}

Keywords: Worlds of Labor - Historiography - Rio Grande do Sul - Brazil

* Este artigo incorpora e atualiza discussões levantadas nas teses de doutorado defendidas pelos autores na área de História Social do Trabalho, em 2004 e 2006, respectivamente, ambas orientadas pelo Prof. Dr. Michael McDonald Hall, com bolsas CAPES. Ver: KONRAD, Diorge Alceno. O fantasma do medo: o Rio Grande do Sul, a repressão policial e os movimentos sócio-políticos (1930-1937); KONRAD, Glaucia Vieira Ramos. Os trabalhadores e o Estado Novo no Rio Grande do Sul: um retrato da sociedade e do mundo do trabalho (1937-1945).

** Professora Adjunta do PPG em História na Linha de Pesquisa Migrações e Trabalho, do PPG em Patrimônio Cultural e do Departamento de Documentação da Universidade Federal de Santa Maria (UFSM); Doutora em História Social do Trabalho pela UNICAMP. Endereço Eletrônico: glaucia-k@uol.com.br

*** Professor Associado do PPG em História na Linha de Pesquisa Migrações e Trabalho e do Departamento de História da UFSM; Doutor em História Social do Trabalho pela UNICAMP. Endereço Eletrônico: gdkonrad@uol.com.br 
Não há como recortar uma história do trabalho puramente "regional" sobre o Brasil pós-1930. A recente história do trabalho no Rio Grande do Sul muito tem se orientado pela reivindicação de colocar em novo patamar analítico a articulação dos resultados das pesquisas regionais. O desenvolvimento da historiografia vem demonstrando que região, regionalismo ou história regional tem mais a ver com recortes políticos ou metodológicos, que no fundo geralmente mascaram dimensões mais amplas.

A história recente do trabalho tem intentado romper concretamente com os "centros definidores de sentido", reivindicados por Silvia Petersen, cruzando as fronteiras e transcendendo qualquer estudo de caso que procura classificar a priori uma história como "regional" ou "nacional". ${ }^{1}$ Em obra mais recente, "Cruzando fronteiras: novos olhares sobre a história do trabalho", inspirada nessa perspectiva, os organizadores voltam à questão, indicando que "o desenvolvimento da pesquisa sobre o tema em regiões e localidades até recentemente não estudadas [...] começa a criar, pela primeira vez, condições para uma história do trabalho efetivamente nacional [...] para propor explicações para o país como um todo".2

Ao mesmo tempo, uma síntese historiográfica mais aprofundada tem desvelado a complexidade antitética desse período, demonstrando que houve um intenso jogo de continuidades e rupturas não restritas a um marco divisório e datado pelo marco simbólico de 1930. Porém, esse marco ainda é referendado por boa parte da historiografia como "o alfa-ômega da história dos trabalhadores", como bem colocou Fernando Teixeira da Silva. ${ }^{3}$

No plano teórico, a reflexão pretendida aqui busca a complexidade e a heterogeneidade que foi o pós-1930 na formação e no processo histórico brasileiro, de modo a captar o "centro" e a "periferia" numa complementaridade contraditória. Seria um equívoco concluir que apenas em uma "historiografia nacional" se ressaltam as semelhanças, enquanto que numa "historiografia regional" aparecem as diferenças. Ambas, mesmo que aparentemente críticas, ainda ocultam ou mitificam as contradições sociais e políticas dos processos históricos reais.

Por isso, as vitórias ou derrotas dos trabalhadores nos anos de 1930 a 1945, por meio da conquista de direitos ou da repressão às suas greves, das prisões e do fechamento ou da legalização oficial de seus sindicatos, etc., não estavam dadas $a$ priori em nenhum momento. Mesmo quando foram derrotadas, geraram acúmulo de consciência e cultura para novas lutas de classes.

Por exemplo, no caso da legalização dos sindicatos, Alexandre Fortes, ao estudar os metalúrgicos em Porto Alegre, já demonstrou que, durante o primeiro governo Vargas, "longe de ser um processo linear”, a legalização dos sindicatos foi marcada pela "disputa em torno da re-apropriação de práticas e discursos operários, empresariais e estatais”. Para o autor, a luta do começo da década de 1930 "deixou raízes tão profundas quanto aquelas do corporativismo na consciência de classe dos trabalhadores brasileiros". ${ }^{4}$

1 PETERSEN, Silvia Regina Ferraz. Cruzando fronteiras: as pesquisas regionais e a história operária brasileira. In: ARAÚJO, Angela M. C. (Org.). Trabalho, cultura e cidadania: um balanço da história social brasileira. São Paulo: Scritta, 1997, p. 85-103.

2 FORTES, Alexandre; LIMA, Henrique Espada; XAVIER, Regina Célia; PETERSEN, Sílvia Regina Ferraz. Cruzando fronteiras: novos olhares sobre a história do trabalho. São Paulo: Fundação Perseu Abramo, 2013, p. 08.

3 SILVA, Fernando Teixeira da. Operários sem patrões: os trabalhadores da cidade de Santos no entreguerras. Campinas: Ed. da Unicamp, 2003, p. 41.

4 FORTES, Alexandre. Revendo a legalização dos sindicatos: metalúrgicos de Porto Alegre (1931-1945). In: FORTES, Alexandre (et al.) Na luta por direitos. Estudos recentes em história social do trabalho. Campinas: Ed. da UNICAMP, 1999, p. 38-42. 
Essa compreensão se torna mais necessária ainda quando a historiografia trata de temas como repressão político-policial e resistências dos diversos movimentos, formados por projetos e práticas históricas em disputa, em torno da luta das classes sociais. Assim, tanto a repressão quanto as resistências não resultaram somente em imposições, muito menos em trajetórias lineares, singulares e evolutivas, mas fazem parte de um processo que engloba conservação/transformação social, ora autonomizadas do Estado, ora submetidas a ele e às suas classes dominantes.

Por outro lado, a historiografia e a produção da área das Ciências Sociais, tanto a "nacional" como a "rio-grandense", contribuíram para certo hiato no que diz respeito ao Estado Novo e às suas relações com o mundo do trabalho. No caso "nacional", na maioria das vezes, concluindo que os trabalhadores mantiveram-se passivos diante da Ditadura, alicerçados na tese do compromisso ou do "pacto", além do atrelamento com a legislação sindical e trabalhista corporativista, com marca de heteronomia da classe, como veremos em obras clássicas de Evaristo de Moraes Filho, Azis Simão, Leôncio Martins Rodrigues, Luiz Werneck Vianna, Heloísa Helena Martins, Keneth Erickson, Sérgio Amad Costa, Angela de Castro Gomes e outros ; no caso "regional", além de repetir tal assertiva, praticamente não há abordagens e maiores desenvolvimentos de estudos sobre o período.

\section{A historiografia e a questão dos direitos}

A separação entre direitos sociais e direitos civis, priorizando e evidenciando aqueles, foi uma constante nos discursos e nas práticas governamentais entre 1930 e 1937, o que levava o governo a ampliar a sua base de apoio com os trabalhadores. Por sua vez, parte dos trabalhadores e dos movimentos sindicais, foi compreendendo que numa realidade anterior destituída de direitos sociais as novas conquistas oriundas da legislação trabalhista, reivindicação de tantos anos, representavam conquistas históricas substanciais.

Mesmo assim, questionamos uma historiografia que tem reconhecido que no período aqui estudado se avançou em direitos sociais, ao passo que, em se tratando de direitos políticos, as conquistas foram mínimas.

A dicotomia entre avanços sociais e poucas conquistas de direitos políticos foi reforçada na análise elaborada por José Murilo de Carvalho, ao afirmar que entre 1930 e 1945 os direitos sociais estiveram na "dianteira", enquanto que o avanço dos direitos políticos foi "limitado e sujeito a sérios recuos". ${ }^{5}$ Não se trata de negar em absoluto essa característica do processo histórico desse período. O fato é que no cenário da luta de classes pós-1930 foi preciso construir uma hegemonia na qual a correlação de forças deveria impedir que os trabalhadores tivessem um projeto alternativo de poder político e social, o qual passava, intrinsecamente, por novas conquistas de direitos políticos. Qualquer reivindicação nesse sentido, sempre foi tratada pelos que dominavam o aparelho de Estado como "subversão da ordem", ou ainda como "caso de polícia". Aqui, e somente aqui, a vigilância, a repressão e a criminalização dos movimentos sociais e políticos de oposição se tornavam intensas, inclusive para limitar o alcance dos próprios direitos sociais reivindicados.

É significativo que na obra já citada de Carvalho, assim como em Gomes ${ }^{6}$, a parte dedicada aos direitos sociais seja tão extensa, enquanto que a da luta pelos direitos políticos seja tão restrita.

5 CARVALHO, José Murilo de. Cidadania no Brasil: o longo caminho. 4 ed. Rio de Janeiro: Civilização Brasileira, 2003, p. 110-26.

6 GOMES, Angela de Castro. Burguesia e trabalho: política e legislação social no Brasil (1917-1937). Rio de Janeiro: Campus, 1979. 
Entendemos que a separação entre direitos sociais e direitos políticos, assim como a separação da sociedade civil da sociedade política, objetivam essencialmente a manutenção do poder de Estado, a fim de assegurar a reprodução das próprias relações sociais e econômicas estabelecidas. Não se trata de ver o "Estado como vilão", nem a sociedade como "vítima indefesa".?

O núcleo interligado de análise, entre direitos sociais e trabalhistas e direitos político-civis, entre movimentos sociais e movimentos políticos, e entre sociedade civil e sociedade política foi a pretensão desenvolvida por $\operatorname{Konrad}^{8}$, de crítica à análise de José Murilo de Carvalho. ${ }^{9}$

Historicamente a cidadania tem sido limitada no Brasil. Porque quando se têm conquistas de direitos sociais, elas não vêm acompanhadas no mesmo grau de direitos políticos e civis. $\mathrm{E}$, quando a conjuntura não tem sido favorável para manter os níveis de mobilização social, muitos dos direitos conquistados são ameaçados de ser retirados.

José Murilo de Carvalho, ao se referir ao período de 1930 a 1945, e orientado genericamente pela obra "Cidadania, classe social e status", de T. H. Marshall, explica que, se comparado com o exemplo inglês, no Brasil "o governo invertera a ordem do surgimento dos direitos". Isso porque inseriu "o direito social antes da expansão dos direitos políticos", pois "os trabalhadores foram incorporados à sociedade por virtude das leis sociais e não de sua ação sindical e política independente". ${ }^{10}$

Por que no autor não há uma linha no segundo capítulo ("Marcha acelerada 1930-1964") sobre a "conquista" de direitos sociais após 1930, justamente como decorrência da ação política e sindical independente, que caracterizou o movimento operário e dos trabalhadores, ao menos até 1934? O problema nessa importante obra do historiador é a escala hierárquica e vertical sobre quais e tais direitos devem vir primeiro: políticos e sociais. No processo de luta de classes, os direitos, sejam eles civis, políticos, sociais, trabalhistas e até individuais, dependem da correlação de forças estabelecida em cada conjuntura dessa luta.

Por isso, avançam e retrocedem sem ser previamente dirigidos por uma única lógica. Separar esses direitos em hierarquias talvez apenas contribua para uma noção de cidadania: aquela que justamente temos nos dedicado a considerar criticamente e que foi hegemônica na "Era Vargas". Uma noção de cidadania e de direito, mantenedora de uma visão homogênea de sociedade que tem sobre ela um Estado pretensamente acima das classes. Uma conceituação de cidadania aberta aos direitos dos trabalhadores, mas que, no máximo, privilegia a construção de uma identidade/consciência nacional em detrimento de uma identidade/consciência de classe dos trabalhadores. A primeira visão, tendo como prioridade a harmonia social, constrói o operário como "trabalhador nacional”. Foi esse o argumento fundamental desenvolvido por Konrad, no artigo "Operários no Rio Grande do Sul (1930-1937): conflitos entre identidade nacional e identidade de classe"."11

7 FERREIRA, Jorge. O nome e a coisa: o populismo na política brasileira. In: FERREIRA, Jorge (org.). O populismo e a sua história: debate e crítica. Rio de Janeiro: Civilização Brasileira, 2001, p. 95-6.

8 KONRAD, Diorge Alceno. O fantasma do medo: o Rio Grande do Sul, a repressão policial e os movimentos sócio-políticos (1930-1937). Tese (Doutorado em História Social do Trabalho). Campinas: IFCH-Unicamp, 2004.

9 CARVALHO, José Murilo de, op. cit., 2003.

10 CARVALHO, op. cit, 2003, p. 124.

11 KONRAD, Diorge Alceno. Operários no Rio Grande do Sul (1930-1937): conflitos entre identidade nacional e identidade de classe. In: Os trabalhos e os dias. Ensaios de interpretação marxista. Passo Fundo: Ed. da UPF/Centro de Estudos Marxistas, 2000, p. 113-61. 
De certa forma, esta visão, de luta dos direitos como consciência de classe, já havia sido desenvolvida por Alexandre Fortes, em "Buscando os nossos direitos...". Trabalhadores e organização sindical na Porto Alegre de 1933 a 1937" de abordagem se deu em torno dos direitos dos trabalhadores metalúrgicos da capital rio-grandense. Nessa mesma linha de interpretação, tem sido desenvolvida parte da historiografia do trabalho que centra a análise na relação entre cidadania e luta por direitos, especialmente no ensaio de Alexandre Fortes e Antonio Luigi Negro, em "Historiografia, trabalho e cidadania no Brasil"13 e na tese de doutorado de Alexandre Fortes, "Nós do Quarto Distrito.... A classe trabalhadora porto-alegrense e a Era Vargas". ${ }^{14}$

\section{A "questão social" e a repressão}

Outro tema importante na historiografia do trabalho tem sido a análise da chamada "questão social". Sobre o Rio Grande do Sul, o trabalho mais importante, e voltado para o período da República positivista, é "O governo do Partido Republicano Rio-Grandense e a questão social”, de César Queirós. Para o autor, a "questão social" é "o conjunto de problemas engendrados pelo surgimento da classe operária em um contexto de crescente industrialização e urbanização", cuja precariedade da situação dos trabalhadores possibilita "a emergência de um movimento operário que passa a reivindicar junto à burguesia e ao Estado melhores condições de vida e trabalho". ${ }^{15}$

Essa argumentação, apesar de clássica, limita seu significado, pois mesmo que partindo da luta entre o capital e o trabalho, ao resumir-se a ela e ao movimento operário, corre-se o risco da retirada da dimensão mais ampla da luta de classes: fenômeno multifacetado e contraditório, que envolve todo o processo de manutenção/revolução da sociedade. Então, uma noção ampliada do significado sobre a "questão social" não nega o centro do conflito entre o capital e o trabalho, mas admitir uma visão reduzida a esse conflito implica não perceber a autonomia relativa do Estado no tratamento da "questão social", com o perigo de se cair numa falsa e simplista dicotomia: Estado repressor/sociedade civil reprimida. Ao centrar-se a análise da "questão social" apenas na busca de melhoria das condições sociais e de trabalho do operariado, a partir da sua inserção nas relações produtivas, corre-se o risco de ignorar a luta política da classe e entre as classes.

Como considera Adalberto Paranhos, os anos de 1930 constituíram o "solo propício ao surgimento da ideologia do trabalhismo" que não nasceu do nada nem foi uma mera "invenção do Estado". Ela só pode ser compreendida se relacionada às circunstâncias históricas, "como parte inseparável da reação de um Estado capitalista que não podia mais subestimar a 'questão social"'. Para o autor, se entrevê, entre as fissuras do discurso oficial, no princípio daqueles anos, "a repercussão,

12 FORTES, Alexandre. "Buscando os nossos direitos...". Trabalhadores e organização sindical na Porto Alegre de 1933 a 1937. Dissertação (Mestrado em História Social do Trabalho). Campinas: IFCH-UNICAMP, 1994.

13 FORTES, Alexandre; NEGRO, Antonio Luigi. Historiografia, trabalho e cidadania no Brasil. In: FERREIRA, Jorge; DELGADO, Lucília de Almeida Neves (Orgs.). O Brasil Republicano. O tempo do nacional-estatismo: do início da década de 1930 ao apogeu do Estado Novo. Livro 2. Rio de Janeiro: Civilização Brasileira, 2003, p. 181-211.

14 FORTES, Alexandre. “- Nós do Quarto Distrito...”. A classe trabalhadora porto-alegrense e a Era Vargas. Tese (Doutorado em História Social do Trabalho). Campinas: IFCH-UNICAMP, 2001, p. XXI-XXI.

15 QUEIRÓS, César Augusto Bubolz. O governo do Partido Republicano Rio-Grandense e a questão social (18951919). Dissertação (Mestrado em História). Porto Alegre: UFRGS, 2000, p. 14. 
mesmo que enviesada, das ideologias e das práticas operárias do pré-1930 no redimensionamento do tratamento dispensado à "questão social"'. ${ }^{16} \mathrm{~A}$ mesma opinião tem Angela Araújo, apenas acrescentando que "como se tratava de preservar uma sociedade pluriclassista, a questão central estava em encontrar uma resposta ao problema da "coexistência das classes"', sendo, nesse sentido, que o projeto corporativista ganhou corpo na década de $1930 .{ }^{17}$

Outro problema é o tratamento sobre a "questão social" como "caso de polícia". Cerqueira Filho entende que a "questão social" era vista como um "caso de polícia", porque aparecia concretamente nas "frestas de uma relação bem construída entre importadores e empresários", expressando "as contradições entre o capital e o trabalho no interior do processo de industrialização capitalista". Sendo a classe operária "uma classe dominada no interior de uma contradição secundária”. No entanto, devido às crises internacionais do capitalismo, como a de 1929, e, sobretudo, com a "Revolução de 1930", quando o Estado passou a praticar estímulos governamentais para a "continuidade do processo de industrialização", a "questão social" tornou-se a "expressão das contradições antagônicas entre empresariado industrial e operariado", não podendo mais "ser subtraída sub-repticiamente ou combatida exclusivamente pela polícia". ${ }^{18}$

Em "O fantasma do medo", Konrad discordou do autor, argumentando que o crescimento da organização dos trabalhadores brasileiros, além do aumento de sua consciência de classe, ampliando as reivindicações na busca de direitos, é a explicação mais razoável para que o Estado e as classes dominantes brasileiras, no período pós-1930, não tratassem a "questão social", exclusivamente, como "caso de polícia". Para o autor, a explicação economicista em relação às mudanças estruturais torna-se limitada, pois retira a dimensão política da luta social em torno do problema. Konrad pergunta, ainda, se a crise capitalista e a mudança de governo explicavam o novo tratamento dado à "questão social": por que a repressão policial às greves e às organizações políticas e sindicais autônomas dos trabalhadores continuou no Brasil da década de 1930?19

Dessa forma, a historiografia precisaria responder qual era a ruptura real e a aparente no tratamento da "questão social" no pós-1930. Konrad, disse que, mesmo que os operários se voltassem mais para a luta dos direitos sociais, em contraposição aos direitos políticos, não havia como se negligenciar a luta por direitos sociais pela classe trabalhadora, igualmente com a luta por direitos políticos. Até porque eram justamente esses direitos políticos que o projeto corporativista procurava deixar em plano inferior, ou simplesmente ignorar. ${ }^{20}$

No processo histórico concreto, o movimento operário e os setores políticos que não fizeram a distinção entre direitos sociais e políticos acabaram atraindo para si a repressão política e a violência policial. Para esses trabalhadores, na década de 1930, continuou a existir uma linha tênue entre a luta por direitos e a repressão político-policial, pois eles sabiam que a conquista dos direitos mantinha-se demarcada pela intermediação/repressão da polícia, uma herança do período anterior.

16 PARANHOS, Adalberto. O roubo da fala: origens da ideologia do trabalhismo no Brasil. São Paulo: Boitempo Editorial, 1999, p. 17-19.

17 ARAÚJO, Angela Maria Carneiro. A construção do consentimento: corporativismo e trabalhadores nos anos 30. São Paulo: Scritta/Fapesp, 1998, p. 119.

18 CERQUEIRA FILHO, Gisálio. A "questão social” no Brasil: crítica do discurso político. Rio de Janeiro: Civilização Brasileira, 1982, p. 58-60.

19 KONRAD, op. cit., 2004, p. 101.

20 Ibidem, p. 102. 
Não se tratava de uma simples continuidade da política repressiva pré-1930. Mas no que tange à classe dominante, no geral, e à fração hegemônica dessa mesma classe, que conquistou o poder político, em especial, a orientação política foi de diretrizes complexas e dialéticas de cooptação, buscando o apoio para o seu projeto político, ou da repressão, quando ocorria oposição ao mesmo projeto.

O argumento sobre as especificidades do Rio Grande do Sul no tratamento da "questão social", dado aos operários no período pré-1930, é insuficiente para explicar o papel dos "gaúchos" como uma "ilha" no tratamento da problemática. A classe dominante gaúcha foi, por quase 40 anos, um dos sustentáculos do coronelismo, principalmente por meio do borgismo. ${ }^{21}$ Tampouco se pode falar de especificidade gaúcha no período pós-1930. Maria Elizabeth Lucas, a respeito dessa questão, diz que

embora na década de 30 o Rio Grande do Sul seja um estado basicamente agropecuário e de incipiente industrialização isto não significa que o movimento operário gaúcho nas suas lutas e reivindicações, se distancie do operário do centro do país, onde o setor industrial estava mais desenvolvido. Ele acompanha as mesmas tendências do operariado do resto do país ao nível de organização e interesse de classe. [...] O que se quer salientar é que no plano das idéias que circulavam entre o operariado da época não há distâncias significativas. ${ }^{22}$

Dessa maneira, temos de questionar a consistência metodológica de realizar um estudo centrado em análises discursivas de documentos "oficiais", tendente a transformar as fontes no próprio processo histórico. O resultado de uma historiografia com essa perspectiva será a reprodução do discurso dos poderes constituídos, como na afirmação de que no pós-1930 a "questão social deixou de ser caso de polícia", argumento governista presente em boa parte da documentação oficial. ${ }^{23}$

No pós-outubro de 1930, a manutenção da ordem continuou tendo um braço importante para a sua realização: a polícia. Não era qualquer polícia, mas uma organização que já vinha sendo desenvolvida durante muitos anos: a polícia política, com funções preventivas e repressivas, cuja finalidade era impedir as reações políticas contra a "ordem e a segurança pública".

Por isso, como explica E. P. Thompson, a repressão e a prisão fazem parte da formação da classe trabalhadora. A perseguição a um movimento social produz a repressão, mas também variadas formas de reação, sendo uma "faca de dois gumes", pois é nos momentos de repressão que se pode falar do amadurecimento de uma "consciência operária diferenciada", baseada na "tenacidade da autopreservação". ${ }^{24}$ Para o historiador, os trabalhadores, com a "sua experiência própria e com o recurso à sua instrução errante e arduamente obtida", vão formando "um quadro fundamentalmente político da organização da sociedade", aprendendo "a ver suas vidas como parte de uma história geral de conflitos". ${ }^{25}$ Geralmente, essa característica

21 Sobre isso, ver: FÉLIX, Loiva Otero. Coronelismo, borgismo e cooptação política. 2 ed. Porto Alegre: Ed. da UFRGS, 1996.

22 LUCAS, Maria Elizabeth. Legislação social e independências ideológicas no movimento operário gaúcho (1930-1937). In: Estudos Ibero-Americanos. O processo revolucionário de 1930, v. VII, ns. 1-2. Porto Alegre: Ed. da PUC-RS, p. 51, 1981.

23 Ver especialmente os fundos de Getúlio Vargas e Lindolfo Collor, encontrados no CPDOC da Fundação Getúlio Vargas (FGV).

24 THOMPSON, E. P. Senhores e caçadores: a origem da Lei Negra. 2 ed. Coleção Oficinas da História. Rio de Janeiro: Paz e Terra, 1997, p. 15-23.

25 THOMPSON, E. P. A formação da classe operária inglesa - III. A força dos trabalhadores. 2 ed. Rio de Janeiro: 
marca a trajetória dos movimentos sociopolíticos dos trabalhadores: conquistas de direitos e repressão têm sido faces de uma mesma moeda.

Nesse período, tanto no Brasil como no Rio Grande do Sul, raros foram os momentos em que a polícia não agiu por meio da vigilância, da espionagem, da violência e da repressão no tratamento de questões políticas e sociais. É isso que a recente historiografia do trabalho tem procurado deixar de ignorar.

Para muitos autores, a "Revolução de 1930" trouxe a "modernidade" pela consolidação do trabalho livre, urbano e mecanizado, uma das bases de sustentação econômica. Porém, a "modernização", que implica também os pilares políticos clássicos da modernidade burguesa, baseados na igualdade de direitos e na democracia participativa, encontrou dificuldades para criar raízes nesse período. A partir de outubro de 1930, boa parte dos direitos continuou a ser antagônica com a noção de segurança pública e/ou manutenção da ordem, mantendo a cisão entre a sociedade e os aparelhos policiais e estatais.

No Brasil, em 1930, para os nossos republicanos, os trabalhadores poderiam ter direitos desde que aceitassem o enquadramento e a incorporação pelo Estado, dentro da mais cara tradição comteana do Estado-Providência. Porém, o problema não estava na organização dos movimentos sociais em si, pois, no caso sindical ela foi até estimulada, mas sim na autonomia de organização dos movimentos sociais, autonomia que o projeto corporativista precisava destruir no início dos anos de 1930. E, mesmo assim, os trabalhadores não deixaram vazia essa arena de luta, pois a busca de direitos econômicos, sociais e políticos não ficou subordinada às supostas "manipulações” do Estado.

Beatriz Loner mostrou uma das práticas das lideranças do movimento operário pós-1930, oriundas ainda da Primeira República: jogar com a ilegitimidade da repressão. Ou seja, a polícia era comunicada previamente dos movimentos e de seu caráter pacífico, como uma forma de "salvaguardar a posição dos grevistas posteriormente, quando a polícia reprimisse". Mas, na maioria das vezes, a violência policial era enfrentada com a reação do operariado, inclusive incentivada pelas lideranças. ${ }^{26}$

\section{Trabalho, historiografia e Estado Novo}

Com poucas exceções, a maioria dos autores que se debruçaram sobre a história dos trabalhadores na República ignorou o período estado-novista, estabelecendo o limite da abordagem no ano de 1937, retomando ou iniciando a análise em 1945. Entre os que se dedicaram ao período, como nos estudos brasileiros da sociologia do trabalho, principalmente a partir de década de 1960, o que foi dito sobre o Estado Novo, em geral, repete o mesmo tom. É com algumas dessas reflexões que dialogamos a partir daqui.

Antes ainda da Sociologia dos anos de 1960, surgiu o clássico "O problema do sindicato único no Brasil', de Evaristo de Moraes Filho, publicado em 1952 e base para a maioria dos trabalhos posteriores. Na obra, o autor compara a Constituição estado-novista com a legislação da Carta del lavoro italiana, concluindo que tivemos, no Brasil, "uma legislação totalmente fascista”. Assim, para o autor, 
durante o período de 1937 a 1945, a liberdade sindical, no que diz respeito à autonomia sindical, "não existia, era inteiramente nula". ${ }^{27}$

Entretanto, é difícil acreditar na tese de que a legislação trabalhista e sindical corporativa do Estado Novo destruiu toda e qualquer tradição de luta e resistência da classe trabalhadora brasileira, simplesmente porque impôs uma nova lógica a ela. Concluiríamos, de antemão, portanto, que os trabalhadores brasileiros, manipulados, cooptados, vigiados e controlados pela Ditadura em nada colaboraram para a sua destruição. Portanto, a contradição fundamental que pôs fim ao Estado Novo restaria apenas ao caráter externo: quem sabe a Guerra Mundial e a luta contra o nazifascismo dos trabalhadores mundiais, exceto os daqui? Ou restaria apenas a oposição liberal ao Estado Novo, o único agente histórico de destruição da Ditadura? Obviamente, essa opção oculta a trajetória de resistência dos trabalhadores. No fundo, essa "leitura" coincide com o arrazoado conservador das classes dominantes brasileiras sobre o período do Estado Novo, no qual os trabalhadores inexistem como classe que constrói consciência e luta por seus direitos, apagando destes a sua história e a sua memória.

Parece-nos que foi, justamente em contraposição ao argumento da absoluta hegemonia dos ministerialistas, ainda em 1955, que Hermínio Linhares escreveu sua "Contribuição à história das lutas operárias no Brasil". O argumento do autor é que, durante o Estado Novo, os trabalhadores do campo e da cidade, mesmo diante das torturas, das prisões, dos espancamentos e do terror, não deixaram se intimidar. Para Linhares, nessa fase houve "anos de revigoramento, de luta". ${ }^{28}$

Destacamos também "Sindicato e Estado", de Azis Simão, resultado de profunda pesquisa, sobretudo em fontes primárias, mesmo que restrito ao caso paulista. Simão argumenta que a institucionalização dos conflitos, principalmente no "esquema corporativista" do Estado Novo, era o que garantia e organizava os direitos, obrigando e restringindo a ação dentro do quadro normativo. Ou seja, aqui, o direito não era um campo de luta, em especial para os trabalhadores no rumo de conquistas, mas uma permissão do Estado, restringindo "as manifestações de desajustamento sob a forma de dissídio declarado perante a Justiça do Trabalho". Como se este não fosse produto das próprias reivindicações históricas do mundo do trabalho.

Assim, a legislação sindical pós-1930 colocou em prática uma "ampla instituição de um sistema heteronomicamente uniformizado". Isso exigia o "poder coercitivo" introduzido pelo Estado mediante a redefinição racional e legal dos fins. Impunha, também, formas e ação dos sindicatos, "unitário e centralizado, passível de controle pelo poder público", construindo quadros burocráticos de direção das entidades, submissos à institucionalidade. Simão conclui que "a oposição oferecida pelas antigas vanguardas do movimento operário" (em especial dos anarquistas) foi "anulada com o advento do Estado Novo". ${ }^{29}$

A seguir esse raciocínio, o sindicato, mesmo sem ignorarmos a sua condição de órgão oficial, ficava limitado às diretrizes governamentais, sem qualquer espaço para a atuação de resistência, submetidos ao "poder de Estado". No entanto, esse tipo de conclusão, mesmo que demonstre a aparência hegemônica da ação

27 MORAES FILHO, Evaristo de. O problema do sindicato único no Brasil: seus fundamentos sociológicos. 2. ed. São Paulo: Alfa-Ômega, 1978, p. 245 e 259-60. (grifos nossos)

28 LINHARES, Hermínio. Contribuição à história das lutas operárias no Brasil. 2. ed. São Paulo: Alfa-Ômega, 1977, p. 75-6.

29 SIMÃO, Azis. Sindicato e Estado: suas relações na formação do proletariado de São Paulo. São Paulo: Dôminus/Ed. da USP, 1966, p. 208-15. 
coletiva dos trabalhadores durante o Estado Novo, não responde às perguntas referentes à luta e à consciência da classe trabalhadora, à busca de direitos e às razões da retomada com força dos movimentos grevistas, antes ainda do término da ditadura do Estado Novo.

Outra obra que abordou a intervenção do Estado na questão operária foi "Conflito industrial e sindicalismo no Brasil", de Leôncio Martins Rodrigues. O autor considera que, no caso brasileiro, para entender a significação da intervenção do Estado, devemos nos reportar para o período do Estado Novo, quando o poder Executivo não se restringiu "a estabelecer os limites 'toleráveis' das reivindicações e participação do proletariado" e "chamou a si a própria organização dos sindicatos". 30

Para Rodrigues, os "vestígios de autonomia" vigentes ainda na década de 1930 desapareceriam em 1937, com o golpe de 10 de novembro, marcados pela Carta Constitucional do Estado Novo, pela criação do imposto sindical em 1940 (regulado em 1942) e pela Consolidação das Leis do Trabalho (CLT) de 1943. Para o sociólogo, a partir de 1937, com essas medidas desaparece "não só o sindicalismo autônomo como o movimento operário". Soma-se a isso, no plano político, "a repressão com violência da militância sindical independente, fazendo com que as correntes políticas de esquerda caíssem na clandestinidade absoluta, inexistindo no interior das associações sindicais qualquer corrente oposicionista à burocracia apoiada e mantida pelo governo". Assim, complementa, somente depois de 1945, com a queda do Estado Novo, é que o movimento operário começou a ressurgir. ${ }^{31}$

Não se trata aqui de ignorar a repressão violenta ou subestimar o controle do Estado sobre os trabalhadores, mas de considerar totalmente perdida a autonomia dos trabalhadores e seus sindicatos (mesmo os oficiais), o que não corresponde com as novas informações que temos tido sobre aquele momento da formação social brasileira. ${ }^{32}$ A resistência e a autonomia, que, por sua vez, também não podem ser absolutizadas, fazem parte da trajetória de lutas por direitos e resistência da classe trabalhadora. $O$ discurso governista do fim da luta de classes não encontrava correspondência na disposição de confronto de muitas lideranças clandestinas dos trabalhadores, bem como de reivindicações de operários comuns.

José Albertino Rodrigues, em "Sindicato e desenvolvimento no Brasil", publicado no final da década de 1960, destoa um pouco das interpretações problematizadas acima. Considera que o Estado Novo, apesar de ter uma orientação geral de tipo fasciocorporativista, a partir de implantação e incorporação ipsis litteris de dispositivos da Carta del Lavoro da ditadura comandada por Benito Mussolini, questiona a "repetida afirmação de que a legislação trabalhista legada por Vargas foi uma generosa concessão à classe trabalhadora no Brasil”.

Ao demonstrar a "pujança e a combatividade do movimento operário antes de 1930", Rodrigues observou que "os grandes temas da moderna legislação do trabalho vinham sendo levantados desde o começo do século e por eles se bateram denodadamente os militantes sindicais da época". Dessa forma, para o autor, a legislação getuliana não foi nem inovadora nem "foi ofertada generosamente às classes trabalhadoras, sem que a estivessem desejando ou sem que tivessem

30 RODRIGUES, Leôncio Martins. Conflito industrial e sindicalismo no Brasil. São Paulo: Difel, 1966, p. 114-5 e 156. (grifos do autor)

31 Idem, p. 161-4.

32 Aqui, indicamos as teses já citadas: KONRAD, Diorge Alceno. O fantasma do medo...2004; KONRAD, Glaucia Vieira Ramos. Os trabalhadores e o Estado Novo no Rio Grande do Sul...2006. 
lutado por ela". Assim, o mito e a persistência de afirmações contrárias podem ser explicados "pelo clima artificial que o Estado Novo criou em torno do assunto". 33

Por outro lado, Rodrigues considera que "o sindicato se descaracterizou como órgão de defesa da classe operária", processo que foi feito "apesar de uma larga dose de politização das classes trabalhadoras". Tudo isso, segundo o autor, resultou em um movimento no qual "o espírito de conquista foi substituído pelo apego ao que existia". Por isso, para o sociólogo, quando no Brasil começou "a se desenvolver a legislação social trabalhista", os sindicatos começaram "a perder sua liberdade e autonomia". ${ }^{4}$

Porém, o desarmamento do "espírito" dos trabalhadores não é sentido quando os atores em poucos anos retornaram às ruas, reivindicando maiores direitos e fim do arrocho salarial, com mobilizações radicalizadas que levaram às grandes greves de 1945, mesmo que ainda proibidas pela vigência da Constituição de 1937. Como explicar que a total falta de liberdade e autonomia sindical dos trabalhadores, mesmo considerando-se a heterogeneidade da classe, levou-os em pouco tempo a um novo patamar de lutas? A resposta pode estar na contraposição de formas subterrâneas da liberdade, que deixavam margem de autonomia para os trabalhadores, ou mesmo para os sindicatos, mesmo que controlados de forma heterônoma.

Há de se convir que esses opostos têm sido insuficientes para explicar as contradições e as lutas do mundo do trabalho no processo histórico brasileiro, bem como a transformação contínua da classe trabalhadora. No Estado Novo não poderia ser diferente. As novas fontes abertas ao público ${ }^{35}$, especialmente as de origem policial, ou a releitura de documentação clássica ${ }^{36}$, bem têm demonstrado essa insuficiência, mesmo que o discurso do Estado da época não reconhecesse o direito dos indivíduos, muito menos a luta de classes, insistentemente mantidas na experiência dos trabalhadores.

As análises da década de 1960, deixadas de lado durante os anos mais repressivos da Ditadura Civil-Militar pós-1964, voltaram a referendar muitas interpretações sobre os trabalhadores do Brasil durante o Estado Novo. Sobretudo, a partir do final da década de 1970 e início dos anos de 1980.

Luiz Werneck Vianna, no clássico "Liberalismo e sindicato no Brasil”, considerou o Estado Novo, para ele iniciado para os trabalhadores ainda em 1935, como um Estado que impôs a "completa subordinação", o "esmagamento da política independente" das classes subalternas e a "manipulação ideológica" dos setores sociais da pequena propriedade. ${ }^{37}$

Depreende-se do autor que a heteronomia estava absolutizada na Carta Constitucional, a qual era referendada nos discursos oficiais, em especial nas alocuções de Vargas, mobilizando-se agora a classe operária "para o interior dos sindicatos postos sob o controle do Ministério do Trabalho". Nesse caso, a classe estava submetida a uma lógica concebida "para ser um mero sistema elementar dos direitos do trabalho", mas que se transformou no seu "único direito". 38

33 RODRIGUES, José Albertino. Sindicato e desenvolvimento no Brasil. Coleção Ensaio e Memória, n. 22. 2. ed. São Paulo: Símbolo, 1979, p. 77-8.

34 Ibidem, p. 78 e 93.

35 Aqui, trata-se especificamente das fontes da polícia política, abertas ao público a partir de 1993, sobretudo a partir do Arquivo Público do Estado do Rio de Janeiro (APERJ).

36 Os fundos de Getúlio Vargas, Lindolfo Collor, Oswaldo Aranha, Flores da Cunha, Filinto Müller e outros, encontrados no CPDOC da FGV, e os fundos Borges de Medeiros/Sinval Saldanha e Governantes/ Correspondência de Governantes, presentes no Arquivo Histórico do Rio Grande do Sul (AHRS), são exemplo desse tipo de documentação.

37 VIANNA, Luiz Werneck. Liberalismo e sindicato no Brasil. 2. ed. Rio de Janeiro: Paz e Terra, 1978, p. 213-4.

38 Idem, p. 221-2. 
Annez Andraus Troyano caracterizou o movimento sindical brasileiro, após o início do controle das atividades sindicais, a partir de 1930, ocorrido por meio da influência do desenvolvimento industrial sobre o conjunto da sociedade, decorrendo daí "as tentativas de colaboração entre o capital e o trabalho". Para Troyano, um "operariado relativamente pequeno e ainda fraco do ponto de vista organizacional" auxilia para que o Estado crie "instrumentos de controle do movimento operário". 39

Realmente é inegável que o objetivo central do Estado Novo, no que diz respeito ao movimento sindical e à classe trabalhadora, era o seu controle absoluto. Porém, apesar do amplo apoio que teve o projeto varguista, o governo e os industriais que o defenderam esqueceram-se de combinar com o adversário o resultado final desse jogo. Nem todos os trabalhadores consideravam que a legislação trabalhista, corporativa e de inspiração fascista era uma simples "doação" de Vargas, mas resultado de suas lutas por direitos, um direito armazenado na cultura política de luta dos trabalhadores.

Já é sabido que nem a repressão nem a cooptação do Estado Novo impediram a resistência dos trabalhadores que, mesmo represados em alguns momentos, voltaram a abrir as comportas de suas reivindicações históricas por liberdade e autonomia sindical e por direitos sociais trabalhistas mais ampliados, sempre encontrando brechas para novos pleitos. Apenas nove anos separaram a leitura brasileira da legislação fascista para o mundo do trabalho e a retomada democrática de 1945.

O estudo de Heloísa Helena Martins, "O Estado e a burocratização do sindicato no Brasil”, surgido também no final da década de 1970, em relação ao Estado Novo, considerou que, nesse período, houve "a elaboração de uma concepção da organização e da função do sindicato" que retirou deste, em primeiro lugar, "a sua principal arma política, que é a greve". Ao mesmo tempo, restringiu "a atuação política das entidades sindicais à área das relações de trabalho", principalmente a partir do decreto de sindicalização de 1939, quando o sindicato passou a ter uma "atuação essencialmente administrativa, com funções delegadas do Estado". Mesmo assim, para a autora, que não desenvolve este importante tema, a ação política não desapareceu. Apenas ficou restrita, "se processando não mais através da ação direta contra o patronato, mas dentro da área do Estado, que aparece como uma instituição interposta no confronto entre patrão e operário", por intermédio da Justiça do Trabalho. ${ }^{40}$

Em "Sindicalismo no processo político no Brasil", Kenneth Erickson considera que as leis trabalhistas, iniciadas a partir de 1930 e consolidadas com o Estado Novo, principalmente com o ataque do ministro do trabalho Marcondes Filho ao pluralismo sindical, serviram para "demonstrar a fraqueza inerente a um movimento sindical imposto de cima para baixo como para sugerir que o pluralismo do sistema trabalhista subtraía os sindicatos ao controle de Vargas", o que demonstrou, para o autor, que a sucessão da legislação trabalhista básica "retardou a mobilização da classe trabalhadora". Assim, o conjunto dessas leis, de estrutura corporativista, alicerçado no tripé sindicatos, previdência social e Justiça do Trabalho, possibilitou "os mecanismos mais importantes para o controle do Estado sobre a classe trabalhadora". ${ }^{41}$

39 TROYANO, Annez Andraus. Estado e sindicalismo. Coleção Ensaio e Memória, n. 12. São Paulo: Símbolo, 1978, p. 29-40.

40 MARTINS, Heloísa Helena de Souza. O Estado e a burocratização do sindicato no Brasil. São Paulo: Hucitec, 1979, p. 48-9.

41 ERICKSON, Kenneth Paul. Sindicalismo no processo político no Brasil. São Paulo: Brasiliense, 1979, p. $43-6$ e 56. 
A novidade, na hipótese levantada por Erickson de que a legislação trabalhista retardou a mobilização dos trabalhadores, merece alguns comentários. A valer essa conjectura, o direito incorporado na legislação trabalhista não passa de um ardil para a cooptação e para o controle dos trabalhadores. Ora, a tradição de luta do movimento operário e sindical brasileiro parece desmentir o autor, pois antes de ser uma doação estatal, greves, mobilizações, e lutas - institucionais ou não - marcou a história da classe trabalhadora por esses direitos. Antes de a legislação retardar a mobilização, foi justamente a mobilização que acelerou a conquista da legislação.

Para Maria Pena, em obra do início da década de 1980, o "controle dos sindicatos e dos mecanismos de mobilização popular durante o Estado Novo" impediu que "os grupos de trabalhadores pudessem, durante certo período, lutar ou mesmo manifestar-se em torno das reivindicações que lhes eram próprias". Mesmo que a autora esteja correta em considerar que os "sindicatos, corporativamente organizados, eram tratados como instrumento de cooperação com o Estado", não podemos seguir a tese incondicional de que Estado Novo combinava apenas com falta de luta ou ausência de reivindicações. ${ }^{42}$

Sérgio Amad Costa, em "Estado e controle sindical no Brasil", parte do pressuposto de que o Estado é agente do controle sindical, utilizando como instrumento mais eficaz para isso a norma jurídica por meio da legislação sindical. O autor reconhece, por outro lado, que as normas jurídicas referentes ao mundo do trabalho também exercem uma "função de agente transformador do meio, quando editadas atendendo às novas necessidades sociais", alterando, ao menos, "uma parte do sistema de controle social". 43

Não sancionamos a tese de Angela de Castro Gomes: em meados do Estado Novo, o governo e as massas populares em torno da legislação trabalhista colocaram em novo patamar a sua relação, levando à consolidação do trabalhismo e à retomada do vigor sindical, por meio de um "pacto" que reafirma o "controle das massas".44 Essa hipótese é profundamente problemática quando não aborda fatores como repressão policial ${ }^{45}$ e luta clandestina dos trabalhadores e suas correntes políticas correlatas. Sem levar em conta que a ideia de "pacto" conforma e generaliza a classe trabalhadora como se ela aceitasse de forma pacífica o fim da sua luta de classes por direitos, tornando-se um apêndice de um agente histórico abstrato, o Estado.

As considerações de Angela de Castro Gomes deixam em aberto algumas questões. Primeiro, se a intenção do Estado realmente se concretizou, porque em menos de dois anos o movimento operário retomou a defesa da liberdade sindical? Segundo, por que o "pacto social" não impediu a mobilização dos trabalhadores por direitos estabelecidos na legislação e por melhores condições de vida e de salários? ${ }^{46}$

42 PENA, Maria Valéria Junho. Mulheres e trabalhadoras: presença feminina na constituição do sistema fabril. Rio de Janeiro: Paz e Terra, 1981, p. 163.

43 COSTA, Sérgio Amad. Estado e controle sindical no Brasil. São Paulo: T. A. Queiroz, 1986, p. 01-02.

44 Sobre isso, ver o texto de Gomes (In: FERREIRA, 2001, especialmente p. 41-2 e 48), no qual a autora afirma que "o pacto trabalhista, pensado ao longo do tempo, tem nele, de modo integrado, mas não redutível, tanto a palavra e a ação do Estado (que sem dúvida teve o privilégio de desencadeá-lo), quanto a palavra e ação da classe trabalhadora, ressaltando-se que nenhum dos dois atores é uma totalidade harmônica, mantendo-se num processo de permanente re-construção".

45 Sobre a repressão policial no período aqui recortado, ver a obra clássica: CANCELLI, Elizabeth. O mundo da violência. A polícia da Era Vargas. Brasília: Ed. da UNB, 1993.

46 Cabe aqui repetir parte da crítica feita por Alexandre Fortes (grifos do autor), em passagem que melhor resume a perspectiva discutível que fundamenta a tese de Castro Gomes: "o fato é que, por sua ênfase na disputa entre discursos e no papel do Estado como enunciador do lugar da classe trabalhadora no pós-30, $A$ invenção do trabalhismo [...] estranhamente, para um trabalho que reivindicava inspiração thompsoniana, a luta de classes em geral faz nele apenas uma pálida figuração, os capitalistas estando completamente ausentes". 
Mesmo que o conjunto da obra demonstre em diversas passagens o contrário, "Nós do Quarto Distrito...", de Alexandre Fortes, chega a afirmar que "o funcionamento do sindicato durante o Estado Novo perdeu qualquer vínculo com as lutas dos trabalhadores". 47

Pensamos que não se pode confundir controle estatal dos sindicatos com a convicção dos trabalhadores de que, independentemente das circunstâncias, os sindicatos dos trabalhadores são para a classe, no capitalismo, instrumentos de defesa de direitos, estando atrelados ao Estado e ao patronato ou sendo autônomos. Dessa forma, acreditamos que os conceitos de "retomada" e "reconstrução", mesmo que importantes, são ainda insuficientes para explicar as greves de 1945.

Preferimos apostar na hipótese de que, na verdade, os trabalhadores de Porto Alegre (e de muitos lugares do Rio Grande do Sul), diante da intensa repressão, estavam acumulando força de resistência na primeira metade do Estado Novo para, em um segundo momento, continuar em novos patamares as suas lutas por direitos, inclusive radicalizando com as greves. Até porque seria contraditório não perceber "nenhum vínculo" dos sindicatos "com as lutas", se seguimos a concepção thompsoniana de que o direito e a sua defesa são campos de lutas.

Como escreveu Hélio da Costa em “Em busca de memória”, “o período que se inaugura com a crise do Estado Novo não pode ser entendido como período de trevas onde a autonomia operária só pode ser lida à luz de enunciados daqueles que proclamam a sua representação". Afirmar a "existência da autoconstrutividade da classe trabalhadora, demonstrada nas suas intermináveis lutas", como propõe o autor, resgatando "as várias lutas levadas adiante pelos trabalhadores durante o Estado Novo" e "os conflitos travados nos locais de trabalho ainda sob forma fragmentada e dispersa", é perceber que a resistência carrega consigo "características que estarão presentes nas lutas ulteriores do movimento operário”. Assim entenderemos melhor o "papel desempenhado pelas grandes mobilizações operárias no contexto da democratização do país, que colocavam em questão os limites da democracia anunciada naquele período" e o "papel destacado das organizações por local de trabalho, sobrepondo-se às entidades sindicais relegadas a um papel coadjuvante nas explosões grevistas que marcaram o final do Estado Novo". ${ }^{48}$

Silvia Petersen e Maria Elizabeth Lucas, em "Antologia do movimento operário gaúcho, 1870-1937”, apesar de não abordarem o Estado Novo, fazem uma aproximação com o período. Consideram que, com o golpe de 1937, se prenunciou "a contenção a ser experimentada pelo movimento operário autônomo durante a vigência da ditadura Vargas", situação que "só seria revertida com o processo de redemocratização do país a partir de 1945".49

Ana Beatriz Loner, em "Classe operária: organização e mobilização em Pelotas: 1888-1937” também se aproxima, em seu estudo, do período do Estado Novo, mesmo não desenvolvendo sobre ele. No entanto, faz várias considerações que de certa forma seguem a mesma argumentação de Petersen e Lucas. Considera que a "implantação da estrutura sindical oficial foi o grande fator delimitante da atuação do movimento operário" na década de 1930. Para a historiadora, "os males advindos do

47 FORTES, Alexandre. op. cit., 2004, p. 437.

48 COSTA, Hélio da. Em busca da memória: comissão de fábrica, partido e sindicato no pós-guerra. São Paulo: Scritta, 1995, p. 9 a 11.

49 PETERSEN, Silvia Regina Ferraz; LUCAS, Maria E. Antologia do movimento operário gaúcho (1870-1937). Porto Alegre: Ed. da UFRGS, 1992, p. 481-2. 
atrelamento sindical se fizeram sentir precocemente, dando início a uma desestabilização interna do movimento", o qual, "de um centro interno, baseado na força de seu número e na sua capacidade de luta, vai passar a reagir e atuar em função de um centro externo: o Estado". ${ }^{0}$

Sabemos que a autonomia dos trabalhadores e o refluxo sindical são constatações importantes, mas ainda insuficientes para explicar a atuação dos trabaIhadores entre 1937 e 1945, tanto no âmbito "nacional" como no "regional". Esse pressuposto, que marcou também a historiografia gaúcha, ao menos até o início da década de 1990, na área do trabalho, ainda referenda historiadores de outras linhas de pesquisa, o que impossibilitou durante muito tempo o alargamento da compreensão sobre os trabalhadores gaúchos durante a ditadura varguista. $O$ resultado mais imediato, com poucas exceções, foi o salto dos estudos sobre os trabalhadores, que de 1937, quando "autônomos" e "resistentes", retornaram ativos apenas oito ou nove anos depois.

Não é sem significado que um dos mais recentes estudos sobre o mundo do trabalho no Rio de Janeiro efetue esse salto, pois "Trabalhadores em greve, polícia em guarda”, coordenado por Marcelo Badaró Mattos, apresenta estudos de 1850 à década de 1920 e depois de 1945 a $1964 .{ }^{51}$ Sobretudo, quando sabemos que a relação entre repressão da polícia política e movimento operário e sindical e a relação identidade de classe e formação da classe trabalhadora foram tão importantes no Primeiro Governo Vargas, não só do Distrito Federal como em vários estados, como o Rio Grande do Sul.

René Gertz, em “O Estado Novo no Rio Grande do Sul”, volta ao argumento defendido por Petersen e Lucas em torno da "contenção" do movimento operário autônomo, só retomado no processo de "redemocratização" de 1945.52

O processo de renovação e de retomada dos estudos sobre os trabalhadores, em parte, nos inspira para perceber questões e problemas que não foram pensados sobre o Estado Novo, colocando ao mesmo tempo velhas questões que a historiografia regional ignorou, mesmo quando os estudos sobre o movimento operário estavam em alta na academia.

A partir dessas considerações, caberia, então, explicar como diante da dominação política e cultural de classe, por entre um Estado ditatorial - o Estado Novo - que visava ao controle dos trabalhadores, estes puderam elaborar uma identidade de resistência, por meio da ação coletiva e individual, seja nos espaços institucionais e ou nos não formais, construindo sua consciência na experiência de luta de classes histórica, no Rio Grande do Sul de 1937 a 1945. Parte dessas questões foi respondida na tese de Glaucia Vieira Ramos Konrad, "Os trabalhadores e o Estado Novo no Rio Grande do Sul: um retrato da sociedade e do mundo do trabalho." 53

Recebido em 24/04/2013

Aprovado em 27/08/2013

50 LONER, Beatriz Ana. Classe operária: organização e mobilização em Pelotas, 1888-1937. Tese (Doutorado em Sociologia). Porto Alegre: UFRGS, 1999, p. 531.

51 MATTOS, Marcelo Badaró (Coord.). Trabalhadores em greve, polícia em guarda: greves e repressão policial na formação da classe trabalhadora carioca. Rio de Janeiro: Bom Texto/FAPERJ, 2004.

52 GERTZ, René. O Estado Novo no Rio Grande do Sul. Passo Fundo: Ed. da UPF, 2005, p. 84-5.

53 KONRAD, Glaucia Vieira Ramos. Os trabalhadores e o Estado Novo no Rio Grande do Sul: um retrato da sociedade e do mundo do trabalho (1937-1945). Tese (Doutorado em História). Campinas: UNICAMP/IFCH, 2006. 